\title{
Service-enhancement Investments and Price Competition in a Hotelling Model
}

\author{
Haiyang Hou ${ }^{1, *}$, Chunyu Zhao ${ }^{2}$ \\ ${ }^{1}$ School of Science, Hangzhou Dianzi University, Hangzhou, China \\ ${ }^{2}$ School of Standardization, China Jiliang University, Hangzhou, China \\ *Correspondence Author, haiyanghou@126.com
}

\begin{abstract}
This paper conducts a study on the competition of service and price under the circumstances of duopoly in the Hotelling linear market, of which the results indicate that the unit variable cost of service level upgrade is large, the service investment undertaken by each firm is insufficient. Besides, we have also taken the situation of government price regulation into consideration, showing that proper price regulation is available to stimulate investment, and the government can apply regulated prices to effectively controlling the level of investment in services.
\end{abstract}

Keywords: Service enhancement, Spatial competition, Price regulation.

\section{Introduction}

In market competition, firms can make use of services to enhance the competitiveness of their own products and transform to service-oriented ones, so as to obtain new sources of value, and this is called "Service Enhancement" (Gann \& Salter, 2002). From the perspective of consumers, service is the "filler" that fills the gap between the functions of tangible products and consumer preferences. Service enhancement can meet the diversified needs of consumers in a better way and improve the utility ( $\operatorname{Lin} \& \mathrm{Wu}, 2005$ ). The phenomenon of service enhancement is prevalent in many markets. A typical example is the medical market, where there is basically no difference between hospitals of the same grade with respect to facility and medical technology. Enhancing hospital services is a new factor in hospital competition, and the investment in service level upgrade enhances the competitive advantage over competitors. In a manner of speaking, the competition among hospitals stimulates investment in service upgrade, thus benefiting patients. Service enhancement contributes to multiple benefits, such as customer satisfaction enhancement, non-technical differentiation advantage establishment and product utilization improvement (Malleret, 2006). Kowalkowski et al. (2017) has summarized and expected for relevant studies, and Chinese scholars have conducted in-depth studies on service enhancement from the aspects of empirical research (e.g., Lin \& Wu, 2009; Jiang \& Li, 2015) and case study (Zhang \& Jiang, 2012).

Sashi and Stem( 1995 )put forward the idea that differentiation advantage depends on product entity, service, and business reputation. Thus, we can see that service is an effective means to enhance product differentiation, and thereby enhance product competitiveness and create more value. Studies on product differentiation can be traced back to the end of 1920s. To give an explanation for the Bertrand Paradox, Hotelling (1978) first proposed the spatial model in economics, that is, adding the spatial difference of product space and the transport cost of consumers into the model of price competition. Salop (1979) conducted a study on the monopolistic competition in the circular market and extended the Hotelling model. Lin and $\mathrm{Wu}$ (2005) adopted a model of economics to discuss the economics connotation of service enhancement, and they established a two-stage game of complete information for service extension and product differentiation in the Salop circular market. In this differentiation model of additional service, the author assumes that there are $n$ consumers uniformly distributed in the circular market with a perimeter of 1 , and three firms located in the same point on the ring at the beginning. Assuming that the tangible products provided by the three firms show no difference, but the firms add extra services to the tangible products by consuming certain resources to show differences. A certain distance that the firm is moving along the ring is adopted to describe the difference derived from the service, and the moving cost for the firm reflects the resource consumed for service augmentation. The results show that the marginal cost for a firm when moving plays a significant effect on its differentiation strategy.

In our model, we study the competition of service and price under the circumstances of duopoly, there into two firms conduct competition in the Hotelling linear market, and their positions are fixed. Firms make a simultaneous determination on service level in the first stage, and then compete on price in the second stage. Certainly, the high service level from firms is not free, it requires necessary capital input from enterprises, including equipment purchase and personnel training, etc. Assuming that the cost of raising service level contains fixed costs and variable costs, it is found that if the unit variable cost of raising service level is large, the service investment undertaken by each firm is insufficient. Besides, we have also considered the model in which price regulation is contained. In many fields of public service, such as the price of medical services, the prices are highly regulated by the government, and firms can't choose their own prices. In this case, it is found that proper price regulation can stimulate investment. Thus, the government can apply price regulation to effectively controlling the investment level of service. 


\section{The Model}

We study a Hotelling-type linear city model. Consumers are distributed uniformly with unitary along the unit interval market $[0,1]$. The location of each consumer is denoted by $x \in[0,1]$. There are two firms supply a physically homogenous good to the market. We assume the marginal costs of production are zero. Firm 1 locates at left extreme $a_{1}=0$ and firm 2 locates at right extreme $a_{2}=1$, i.e., we assume the location is exogenously set at the two extremes of the line. A consumer living at point $x$ pays a transportation cost of $t \cdot\left|x-a_{i}\right|$ when purchasing the product of firm $i$, where $t$ is transport rate. We also assume that each consumer buys only one commodity, that is, demand is inelastic, and the utility obtained from it is $v$, and it is large enough to ensure that no matter how the company prices, the entire market can be covered, and every consumer will purchase behavior. The net surplus of a consumer located at $x$ when buys from firm $i(i=1,2)$ is given by $u_{x}^{i}=v+\alpha s_{i}-p_{i}-t\left|x-a_{i}\right|$, where $s_{i}$ is the service level provided by firm $i(i=1,2)$, and $\alpha$ indicates the preference for the quality of the firm's service. The location $\bar{x}$ of a consumer who is indifferent to the choice between the two firms is given by: $\alpha s_{1}-t \cdot x-p_{1}=\alpha s_{2}-t \cdot(1-x)-p_{2}$, from it we obtain:

$$
\bar{x}=\frac{\alpha}{2 t}\left(s_{1}-s_{2}\right)+\frac{1}{2 t}\left(p_{2}-p_{1}\right)+\frac{1}{2}
$$

When $0 \leq \bar{x} \leq 1$, the demand functions are, respectively:

$$
D_{1}=\bar{x}, D_{2}=1-\bar{x}
$$

In the model, we assume that the firm's service cost includes fixed costs and variable costs. Therefore, the firm's profit function is:

$$
\pi_{i}=\left(p_{i}-c \cdot s_{i}\right) D_{i}-\frac{1}{2} s_{i}^{2}(i=1,2)
$$

In the first stage, the two firms simultaneously choose $s_{i} \in[0,+\infty)(i=1,2)$ which means the service quality firms choose. In the second stage, the two firms simultaneously choose price, $p_{i} \in[0,+\infty)$. The solution concept is a subgame perfect equilibrium through backward induction.

The timing of the game is as follows: In the first stage, the two firms simultaneously choose $s_{i} \in[0,+\infty)$ which means the service quality firms choose. In the second stage, the two firms simultaneously choose price, $p_{i} \in[0,+\infty)$. The solution concept is a subgame perfect equilibrium through backward induction.

In the second stage, with fixed $s_{1}, s_{2}$, The first order condition is:

$$
\begin{gathered}
\frac{\partial \pi_{i}}{\partial p_{i}}=0 \Leftrightarrow \frac{-2 p_{i}+p_{j}+c \cdot s_{i}+\alpha \cdot s_{i}-\alpha \cdot s_{j}+t}{2 t}=0, \\
(i \neq j, i=1,2)
\end{gathered}
$$

Which yields the following Bertrand-Nash equilibrium prices:

$$
p_{i}^{*}\left(s_{i}, s_{j}\right)=\frac{c}{3}\left(2 s_{i}+s_{j}\right)+\frac{\alpha}{3}\left(s_{i}-s_{j}\right)+t, \quad(i \neq j, i=1,2)(4)
$$

Substituting prices (4) into (1), We obtain the market demands of the two firms are:

$$
D_{i}\left(s_{i}, s_{j}\right)=\frac{1}{2}+\frac{\alpha-c}{6 t}\left(s_{i}-s_{j}\right), \quad(i \neq j, i=1,2)
$$

Substituting prices (4) and market demands (5) into the firm's profit function (3), we obtain:

$$
\begin{gathered}
\pi_{i}\left(s_{i}, s_{j}\right)=-\frac{1}{2} s_{i}^{2}+\frac{1}{18 t}\left[3 t+\left(s_{i}-s_{j}\right) \cdot(\alpha-c)\right]^{2}, \\
(i \neq j, i=1,2)
\end{gathered}
$$

In the first stage, firm 1 maximizes $\pi_{1}\left(s_{1}, s_{2}\right)$ w.r.t. $s_{1}$, while firm 2 maximizes $\pi_{2}\left(s_{1}, s_{2}\right)$ w.r.t. $s_{2}$. Notice $\frac{\partial \pi_{i}}{\partial s_{i}}=\frac{1}{9 t}\left(s_{i}-s_{j}\right) \cdot(c-\alpha)^{2}-\frac{1}{3}(c-\alpha)-s_{i}$, and because we are considering symmetrical equilibrium and quality level $s_{i} \geq 0$, so the service level under Nash equilibrium is: when $\alpha>c, s_{i}^{*}=\frac{1}{3}(\alpha-c),(i=1,2) ;$ when $\alpha \leq c$, $s_{i}^{*}=0,(i=1,2)$.

In summary, the perfect Nash equilibrium of subgames obtained by the backward induction method is:

When $\alpha>c$,

$$
D_{1}^{*}=\frac{1}{2}, s_{1}^{*}=s_{2}^{*}=\frac{1}{3}(\alpha-c), p_{1}^{*}=p_{2}^{*}=\frac{c}{3}(\alpha-c)+t,
$$

When $\alpha \leq c$,

$$
D_{1}^{*}=\frac{1}{2}, \quad s_{1}^{*}=s_{2}^{*}=0 \quad p_{1}^{*}=p_{2}^{*}=t,
$$

In summary, we have:

Proposition 1: In the perfect Nash equilibrium of the subgame, if $\alpha \leq c$, No manufacturer invests in improving quality, and the price in equilibrium is equal to the unit transportation cost of a single product; if $\alpha>c$, The quality level under equilibrium is equal to $\frac{1}{3}(\alpha-c)$, has nothing to do with unit transportation cost $t$.

The above analysis takes into consideration how the two companies compete on both price and quality. In many fields of public service, however, it is impracticable for enterprises to be free when choosing prices. For instance, in many countries, prices in the healthcare market and education field are regulated. Thereby, we will study how price regulation affects firms' choice of product quality.

\section{Price Regulation}

In this section, we consider the case in which a regulated price, $M$, is set by the government. The firm's profit function is:

$$
\pi_{i}=\left(M-c \cdot s_{i}\right) D_{i}-\frac{1}{2} s_{i}^{2} \quad(i=1,2)
$$


Two firms choose service quality level $s_{i}$ at the same time. The first order condition is:

$$
\frac{\partial \pi_{i}}{\partial s_{i}}=0 \Leftrightarrow \frac{\alpha M+\alpha s_{2}-2(\alpha+t) s_{1}-t}{2 t}=0,(i \neq j, i=1,2)(10)
$$

We obtain the equilibrium service levels:

$$
s_{1}^{M}=s_{2}^{M}=\frac{\alpha M-c \cdot t}{\alpha \cdot c+2 t}
$$

It can be seen that, if $\alpha \leq c$, As long as the government sets the regulation price $M>\frac{c}{\alpha} \cdot t$, then $s_{1}^{M}=s_{2}^{M}>0$, In other words, although the regulated price $M$ is greater than the equilibrium price $p_{i}^{*}$ in the previous section, but the service level has also been improved; if $\alpha>c$, As long as the government sets a controlled price $M=\frac{c}{3}(\alpha-c)+$ $\frac{(c+2 \alpha)}{3 \alpha} \cdot t<p_{i}^{*}$, then $s_{i}^{M}=s_{i}^{*}=\frac{1}{3}(\alpha-c)$, that is, although the regulated price $M$ is lower than the equilibrium price $p_{i}^{*}$ in the previous section, but the improvement of service level is the same when in equilibrium. From the aspect of economic intuition, it can be understood as the price is regulated, the company only compete on the quality, and firms can't attract consumers depending on a price war. As long as the regulated prices set by the government can lead firms to enough profit, then each firm has a bigger motivation to attract consumers by improving quality. Thus, it has accelerated the competition for quality improvement.

Proposition 2: Compared with the absence of price regulation, if $\alpha \leq c$, the government should set a regulated price higher than the equilibrium price to stimulate firms to improve the quality; When $\alpha>c$, since the cost of quality improvement is low, firms have a strong motivation for quality improvement, and the government can draw enough quality improvement by setting a low regulated price.

\section{Conclusion}

Based on the above analysis, we have found that whether an enterprise improves its service quality in competition often depends on the level of service cost. When the service cost is high, the enterprise will turn to the means of price, so as to achieve the equilibrium of market competition. At this time, it is necessary and effective for the government to facilitate enterprises to improve their own services and enhance consumer welfare through price regulation and other means. For instance, Price control on the education training market will effectively improve training institutions to focus on improving service quality. If no restriction is made, training institutions may fall into the vortex of price competition.

\section{Acknowledgment}

The work was supported by Project of Educational Commission of Zhejiang Province (No. Y201840417) and Key projects of soft science of Zhejiang Province (No. 2021C25035).

\section{References}

[1] Gann, M., Salter, J. Innovation in project-based, service-enhanced firms: the construction of complex products and systems[J]. Research Policy, 2002, 29: 955-972.

[2] Hotelling, H. The stability of competition[J]. Economic Journal, 1978, 39(153): 41-57.

[3] Jiang, Z., Li, N. The impact of service innovation and manufacturing service on the enterprise performance $[\mathrm{J}]$. Science Research Management, 2015, 36(5): 29-37.

[4] Kowalkowski, C., Gebauer, H., Oliva, R. Service growth in product firms: past, present, and future[J]. Industrial Marketing Management, 2017, 60(1): 82-88.

[5] Lin, L., Wu, G. Service-based product differentiation: one mechanism of service-enhancement[J]. Journal of Quantitative and Technical Economics, 2005, 8: 137-147.

[6] Lin, L., Wu, G. Empirical study on "quality compensation" of service-enhancement in manufacturing firms: based on view of resource allocation[J]. Journal of Management Sciences in China, 2009, 12(3): 142-154.

[7] Malleret, V. Value creation through service offers[J]. European Management Journal, 2006, 24(1): 106-116.

[8] Salop, S. Monopolistic competition with outside goods[J]. Bell Journal of Economics, 1979, 10: 141-156.

[9] Sashi, C.M. \&. Stern L.M. product differentiation \& market performance in producer goods industries[J]. Journal of Business Research, 1995, 33: 115-127.

[10] Zhang, H., Jiang, J. Research on Distributor Capability Development of Manufacturing Enterprises for Service-enhancement-A Case Study of Guangzhou Toyota Motor Co., Ltd[J]. Soft Science, 2012, 4(26): 110-113. 